\title{
Vitamin D: A Candidate for the Environmental Effect in Multiple Sclerosis - Observations from Norway
}

\author{
Margitta T. Kampman ${ }^{a, b} \quad$ Magritt Brustad $^{c}$ \\ ${ }^{a}$ Department of Neurology, University Hospital of North Norway, and Institutes of ${ }^{b}$ Clinical Medicine and \\ 'Community Medicine, University of Tromsø, Tromsø, Norway
}

\section{Key Words}

Multiple sclerosis risk factors $\cdot 25$-Hydroxyvitamin D ·

Ultraviolet radiation $\cdot$ Fish $\cdot$ Polyunsaturated fatty acids

\begin{abstract}
Multiple sclerosis (MS) is a chronic disease of the central nervous system, pathologically characterized by inflammation, demyelination, and axonal damage, presumably auto-immune in nature. Complex interactions between genetic susceptibility and environmental factors, such as vitamin D status and primary Epstein-Barr virus infection in adolescence or later in life, probably determine the MS risk. Norway at a latitude $58-71^{\circ} \mathrm{N}$ is a discrete exception to the hypothesis that solar UV radiation exposure, mediated by vitamin $\mathrm{D}$, $\mathrm{CO}$ heres with the latitude gradient seen for MS prevalence. Where UV radiation exposure is low in Norway, vitamin D sufficiency is maintained through a traditional diet providing vitamin $D$ as well as marine omega-3 polyunsaturated fatty acids. This observation supports an environmental interaction between diet and latitude, with vitamin $D$ as the common mediator. The potential roles of vitamin $D$, other environmental exposures, and genes in the complex aetiology of MS are discussed in this review.
\end{abstract}

Copyright $\odot 2008$ S. Karger AG, Basel

\section{Introduction}

Multiple sclerosis (MS) is a chronic disease of the central nervous system affecting young adults, females twice as often as males. The course is usually relapsing-remitting for about 10 years, followed by a secondary progressive phase. The pathogenetic mechanisms have not been fully elucidated. Histology shows Thelper cell type 1-mediated (Th1) chronic inflammation, demyelination, and axonal and neuronal degeneration [1]. The MS risk is dependent on genetic susceptibility $[1,2]$. In Norway, the Sami, an indigenous people in the north of Scandinavia and Russia, are considered 'MS-resistant' [3].

Exposure to environmental factors starts as early as the gestational and neonatal period. Migration studies suggest that the critical window of exposure regarding MS risk is during adolescence [4]. Large population-based studies from Canada have shown that environmental factors act at a broad population level, not in the familial micro-environment [5-7]. A recent review of the environmental risk factors for MS concluded with key roles for UV radiation (UVR), vitamin D, Epstein-Barr virus, and possibly smoking $[8,9]$.

Duration and intensity of sunlight shows a strong correlation with latitude, and the MS prevalence increases with increasing latitude in Europe and in Australia [10, 11]. In Norway, the MS prevalence does not increase with latitude (fig. 1) [12]. Interestingly, the exception of Norway for the latitude gradient of MS parallels the anoma-

Margitta T. Kampman

Department of Neurology

University Hospital of North Norway, PO Box 33

NO-9038 Tromsø (Norway)

Tel. +47 7762 6000, Fax +47 7762 7074, E-Mail margitta.kampman@unn.no 
lous position of Scandinavia for the latitude gradient observed for certain cancers [13].

The effect of UVR is likely to be mediated by vitamin D. For comprehensive reviews of the current evidence for a role of UVR and vitamin D in the pathogenesis and treatment of MS, the reader is referred to recent publications $[9,14]$.

In this paper, we will discuss observations from Norway supporting a role for vitamin D in the complex aetiology of MS. We briefly present evidence supporting the UVR/vitamin D hypothesis for MS risk. We provide data on the vitamin D status in Norway north of the Arctic Circle and an overview of sources of ingested vitamin $\mathrm{D}$ which in Norway are inseparable from sources of marine omega-3 polyunsaturated fatty acids (PUFA). We discuss possible relationships between MS prevalence and dietary patterns and the biological plausibility of a role for vitamin D and omega-3 PUFA in MS pathogenesis. Finally, we summarize the complex interactions between environmental factors and genetic background in MS risk, and we try to answer the question of whether vitamin D sufficiency protects against MS.

\section{The UVR/Vitamin D Hypothesis for MS Risk}

A unifying UVR/vitamin D hypothesis was presented in 1997, based on the geographic distribution of MS worldwide and the exception to this pattern of Norway, supported by data from animal experiments [15].

\section{UV Radiation}

Early ecological studies reported a strong inverse correlation between levels of UVR and MS prevalence, but a number of exceptions to the latitude gradient are recognized $[10,16]$. The most recent prevalence studies show a declining latitude gradient in the United States and also in Europe $[8,10]$. Several studies have assessed the MS risk in relation to UVR exposure. The MS prevalence in Australia and in France could be closely predicted by regional UVR levels [11, 17]. In Tasmania, at latitudes 41$43^{\circ} \mathrm{S}$, a higher sun exposure when aged 6-15 years was associated with a decreased risk of MS [18]. We confirmed these findings in Norway north of the Arctic Circle, where summer outdoor activities in childhood and adolescence decreased the MS risk [12]. A protective effect of childhood sun exposure was also found in female (but not male) monozygotic twin pairs [19]. More indirectly, the mortality from MS was negatively associated with residential and occupational exposure to sunlight [20],

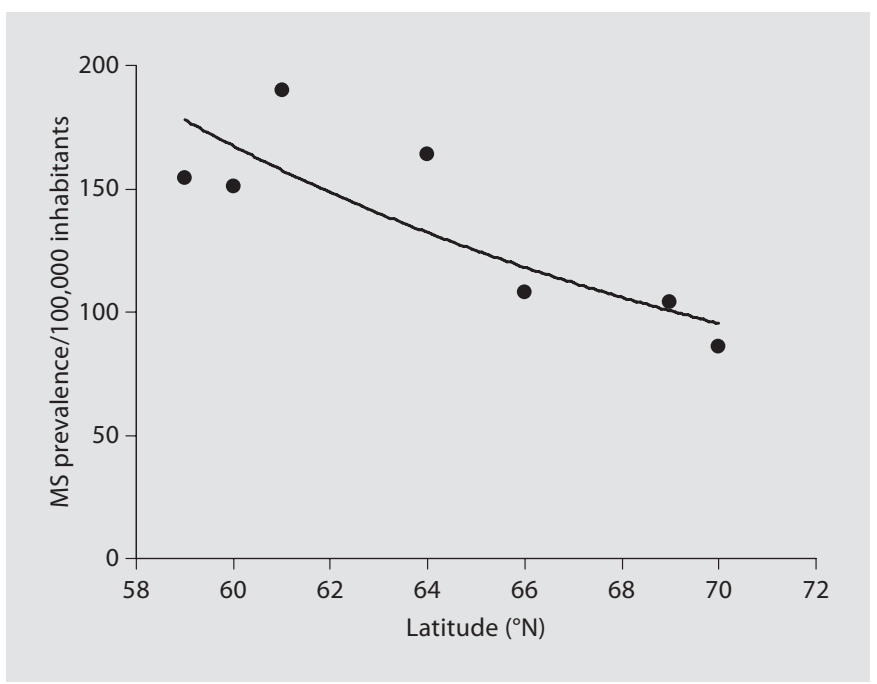

Fig. 1. MS prevalence versus latitude in Norway [12].

and MS was associated with a lower risk of skin cancer, indicating lower exposure to solar radiation in individuals with MS [21]. UVR may exert a protective effect due to its suppressive effects on the immune system. A second possible mechanism is through the involvement of solar UVR in the cutaneous production of vitamin D.

\section{Vitamin D}

Evidence has emerged from epidemiological and experimental studies to support an association of MS with sunlight exposure and the resulting increase in vitamin D [9]. Most notably, higher circulating levels of 25-hydroxyvitamin $\mathrm{D}(25(\mathrm{OH}) \mathrm{D})$, reflecting the vitamin D status, were associated with a lower risk of MS in white people in a prospective nested case-control study. The reduction in risk for the development of MS among individuals with $25(\mathrm{OH}) \mathrm{D}$ concentrations $\geq 100 \mathrm{nmol} / \mathrm{l}$ was considerably stronger at ages $16-19$ years than at ages 20 or older [22]. Maternal vitamin D insufficiency during winter pregnancies might explain the excess of MS in those born in May in northern Europe and Canada [23], and it could be speculated that the vitamin $\mathrm{D}$ status during pregnancy is a factor mediating the maternal parent-of-origin effect in MS susceptibility [5].

\section{Animal Models of MS}

Animal studies of the experimental allergic encephalomyelitis (EAE) model for MS have shown [14] that EAE could be prevented by whole-body UVR and that vitamin D hormone completely inhibited EAE induction and pro- 
gression. A vitamin $\mathrm{D}_{3}$-containing diet inhibited severe EAE only in female mice, indicating a gender difference in the vitamin $\mathrm{D}_{3}$ metabolism in the CNS.

\section{Vitamin D in Other Disorders}

A role for vitamin $\mathrm{D}$ has also been proposed in other immune system-mediated diseases, most convincingly for diabetes type I, rheumatoid arthritis, and inflammatory bowel disease [24]. Moreover, a relationship of vitamin D insufficiency with a wide range of other disorders has been suggested $[13,24,25]$.

\section{Vitamin D Status in Norway at Latitudes $58-71^{\circ} \mathrm{N}$}

Most humans depend on sun exposure (UVB radiation) to satisfy their requirements for vitamin $\mathrm{D}$, but orally ingested vitamin $\mathrm{D}$ can substitute for vitamin $\mathrm{D}$ generated in the skin. At $70^{\circ} \mathrm{N}$, winter sunlight is insufficient for vitamin $\mathrm{D}$ synthesis in the skin during 5 months. In individuals with a low end-of-winter vitamin $\mathrm{D}$ status, cutaneous vitamin $\mathrm{D}$ production in the face starts with rising solar elevation at the beginning of March [26].

Surprisingly, subclinical vitamin D deficiency in wintertime was more common in southern Europe than in Scandinavia in a study comparing elderly people from eleven European countries. Also, the vitamin D status in persons living north of the Arctic Circle in Norway compared favourably with the $25(\mathrm{OH}) \mathrm{D}$ levels measured in central European countries [24, 27]. In Norway, the average vitamin $\mathrm{D}$ intake from diet and supplements equals the currently recommended daily intake of vitamin $\mathrm{D}$ for healthy adults of $300 \mathrm{IU}$ [28]. Good-quality populationbased data allowing regional comparisons of the vitamin D status - plasma 25(OH)D - in Norway are not available.

In North Norway, the main sources of ingested vitamin D were salmon and trout (30\%), cod liver oil supplements (23\%), and fortified margarine or butter on bread (23\%) [27]. At $69^{\circ} \mathrm{N}$, a high dietary intake of vitamin D, especially in winter, largely compensates for the effect of seasonal variation in UVR exposure, thus preventing vitamin D deficiency [29].

A study assessing the relative contributions of dermally generated and dietary vitamin $\mathrm{D}$ showed that sun exposure contributed significantly to plasma $25(\mathrm{OH}) \mathrm{D}$ levels even at latitudes $65-71^{\circ} \mathrm{N}$ [27]. Dietary intake of vitamin D (including supplementary cod liver oil) only predicted plasma $25(\mathrm{OH}) \mathrm{D}$ in women who had not been on holidays in the sun or used tanning beds [27]. In an
MS case-control study in the same region [12], we found that supplementation with cod liver oil was associated with less MS in the subgroup of respondents with little summer outdoor activities.

\section{Dietary Sources of Vitamin D and Marine Omega-3 Polyunsaturated Fatty Acids}

Fatty seafood, egg yolks, and chanterelle mushrooms are the only foods that naturally contain a considerable amount of vitamin D. Other important sources are fortified foods, cod liver oil, and vitamin supplements [24]. In North Norway more than half of the ingested vitamin D comes from fatty seafood and cod liver oil [27], sources that also contain considerable amounts of marine omega-3 PUFA. Thus a possible effect on MS risk of one cannot be separated from the other. Cod liver oil supplements are used regularly by more than one third of the Norwegian population [30]. The most commonly used brand of cod liver oil in Norway contains 400 IU vitamin $\mathrm{D}$ and $1.2 \mathrm{~g}$ omega-3 PUFA/5 $\mathrm{ml}$ recommended daily dose, which is considerably more than in typical preparations available the US [31]. Also fatty fish provides high amounts of vitamin D as well as omega-3 PUFA, for example a 200 -gram serving of farmed salmon contains approximately 640 IU vitamin D and 5 g omega-3 PUFA [32].

Fish consumption is about twice as high in North Norway as in central Europe and the US [33-35]. Although fatty fish only represents about one third of the total fish intake in Norway [33], 'traditional fish eaters' had the highest vitamin $\mathrm{D}$ intake in a comparison of six dietary patterns in Norway [36]. Individuals consuming a diet rich in fish are also likely to eat a fish dish consisting of cod, cod roe, and cod liver oil served during the winter months. One such meal contains approximately 4,000 IU vitamin $\mathrm{D}$, which is more than ten times the recommended daily intake of $300 \mathrm{IU}$ for adults, as well as approximately 14 g omega-3 PUFA [M.B., unpubl. data]. Once a tradition determined by availability, this dish still is commonly consumed in North Norway, especially in the fishing villages [37].

Daily dietary intake of marine omega-3 PUFA varies from $0.1-0.2 \mathrm{~g}$ in the US [38] to approximately $0.9 \mathrm{~g}$ in Norway [39] and 1-2 g in Japan [40]. Intake of both vitamin D and omega-3 PUFA is higher in Norway than in other western countries. 


\section{Can the MS Prevalence Be Related to Dietary Patterns?}

Early epidemiologic studies in Norway reported a lower incidence of MS in the coastal fishing areas in the north than in the inland farming and dairy areas in the south. The butter and animal fat intake in coastal fishing districts was much lower (possibly as much as 65\%) and the total fat intake in the coastal regions somewhat lower (possibly as much as 35\%) than in the inland farming areas [41]. Fifty years later, the MS prevalence in the inland county of Oppland $\left(60-62^{\circ} \mathrm{N}\right)$ was highest in Norway $(190$ cases $/ 100,000$ inhabitants) and almost double compared to that reported from the three coastal counties in the north $\left(65-71^{\circ} \mathrm{N} ; 86-\right.$ 106 cases/100,000 inhabitants) [12]. A strong positive correlation of MS mortality with milk consumption and a weaker negative correlation with fish consumption have been reported from the US and a number of OECD countries [42]. When Lauer [43] reviewed available evidence in 1997, he concluded that an increased MS risk associated with consumption of animal fat, animal protein, and meat was more likely than a protective effect of fish intake. In a retrospective recall questionnaire study [12], we found that consumption of fish three or more times a week during childhood and adolescence was associated with a reduced risk of MS in Norway north of the Arctic Circle. A protective effect of high fish consumption during the year before diagnosis with MS (in women only) was reported from a case-control study in Montreal, Que., Canada [44]. In the Nurses' Health Study [35], the intake of omega-3 fatty acids from fish was unrelated to the MS risk. However, the latter studies report food patterns for a period that is likely to be beyond the main window of environmental impact on MS risk, and fish consumption is much lower in North America than in North Norway. In Japan and Greenland, countries with a high intake of seafood in the traditional diet, MS has been extremely rare, but the incidence of MS is rising in Japan $[16,45]$.

\section{Biological Plausibility of a Role for Vitamin D, Omega-3 PUFA, and UVR in MS Pathogenesis}

Vitamin D, marine omega-3 PUFA, and UVR all have immunosuppressive properties, acting through the prostaglandin pathway.

\section{Vitamin D}

The role of vitamin $\mathrm{D}$ in immunological processes related to MS and EAE has been reviewed by Smolders et al. [14]. Direct genomic signaling by $1,25(\mathrm{OH})_{2} \mathrm{D}_{3}$ occurs through the vitamin D receptor, which is present in multiple cells of the immune system as well as in neurons [46]. Activation of the vitamin $\mathrm{D}$ receptor by $1,25(\mathrm{OH})_{2} \mathrm{D}_{3}$ stimulates a shift from pro-inflammatory Th1 responses to anti-inflammatory Th2 responses.

\section{Marine Omega-3 PUFA}

Marine omega-3 PUFA have potent anti-inflammatory and immunomodulatory properties [47], but with respect to the MS risk, the body of epidemiologic evidence is insufficient, and we have found no reports on the effects of marine omega-3 PUFA in the EAE animal model. A comprehensive review of the role of PUFA in the pathogenesis and treatment of MS has recently been published [48].

\section{UV Radiation}

UVR has complex immunosuppressive properties, mediated by altered expression of cytokines systemically and locally as well as by altered macrophage, dendritic cell, and T cell functions. Possible pathways for beneficial effects of UVR exposure in immune system-mediated disorders that are likely to be independent of vitamin D synthesis have been reviewed by Lucas and Ponsonby [49].

\section{Vitamin D and PUFA and the CNS}

Vitamin D and marine omega-3 PUFA are also involved in brain development and differentiation, neuroprotection, and regeneration [46]. In prospective studies, the fatty acid status during pregnancy has been related to neurological and cognitive function in children [50,51]. The risk of type I diabetes, a Th1-mediated auto-immune disease, was reduced when mothers had taken cod liver oil during pregnancy or when infants were given supplemental vitamin $\mathrm{D}[52,53]$. These findings indicate that low pre- and perinatal vitamin D levels, and possibly the fatty acid status, may have a persistent impact on health outcomes.

\section{Interactions between Environmental Factors and Genetic Background}

No single environmental exposure or genotype causes MS. A complex interaction between more than one environmental factor and individual genetic susceptibility is likely. Adolescence is considered the most vulnerable period for environmental exposures, but also the se- 
quence of interacting exposures might be critical. Environmental changes are the likely explanation of the increasing MS incidence in Norway over the past 50 years [54].

\section{Epstein-Barr Virus Infection}

Interaction between environmental factors has been proposed, for example modulation of the host response to Epstein-Barr virus infection by vitamin $\mathrm{D}$ status [55]. In our case-control study [12], a history of infectious mononucleosis was more common in persons with MS $(8 / 148)$ than in controls $(10 / 295)$. These numbers are too small to prove an association, but among respondents who reported having had infectious mononucleosis, cases more often also reported low outdoor activities during summertime when aged $16-20$ years ( $7 / 8$ cases vs. $4 / 10$ controls).

\section{Cigarette Smoking}

Cigarette smoking before disease onset is consistently associated with an increased risk of MS [9]. The possible mechanisms that relate smoking to MS risk have not been investigated thoroughly. More research is required to determine if smoking has a place in a multifactorial causation model.

A multicentre study of environment and immune function, assessing amongst others UVR exposure, infections, tobacco smoking, and diet, is being planned in Australia, recruiting persons who have experienced a first demyelinating event and matched controls [56].

\section{MS Susceptibility Genes}

The major MS susceptibility genes are located in the HLA region, while polymorphisms in non-HLA genes contribute to the MS risk. MS-associated HLA haplotypes are less frequent in the indigenous Sami [3], and ethnic variations of FC- $\gamma$ receptor and IL-10 polymorphisms between Sami and Norwegian populations have been described $[57,58]$. In Norway, the first diagnoses of MS in Sami people were made in the early 1990s, and the lowest incidence of MS was found in the most northerly county, Finnmark, where the Sami population is highest [59]. Genetic admixture may confer protection also in non-Sami in the northern parts of Norway and Sweden, where the MS prevalence is lower than expected by latitude, given the decreasing north-to-south gradient that is observed across Europe [10, 12, 60]. Still, we find a protective association with UVR exposure and possibly also cod liver oil intake in this population [12]. Genetic susceptibility is considered to be the reason for the high MS prevalence on the Italian island of Sardinia compared with mainland Italy, but also in this highly stable population, exogenous risk factors are believed to contribute to the increasing risk of MS [61].

\section{Gene-Environment Interactions}

Gene-environment interactions, i.e., genetic background modifying responses to environmental factors, are conceivable. The host response to pathogens such as Epstein-Barr virus could be genetically determined [62]. Genes related to vitamin D metabolism might determine individual vitamin D requirements. Vitamin D receptor polymorphisms have been studied, but consistent associations with susceptibility to MS have not been found. Pre- and perinatal vitamin D levels may imprint on the functional characteristics of several tissues or alter the pattern of gene expression [63], providing a possible explanation for seasonality of MS births [23].

\section{Epigenetic Determinants}

Epigenetic determinants, for instance hormones or sex-dependent gene expression, may explain why MS affects women twice as often as men in most populations studied.

\section{Gender Differences}

Gender differences in susceptibility to environmental factors have been reported as well. In an animal study [64], vitamin $\mathrm{D}_{3}$ conferred protection from auto-immune encephalomyelitis only in female mice. The rapid increase of the female/male ratio in MS incidence over the past 50 years in Canada indicates environmental changes that selectively affect women [65]. A protective effect of sun exposure was only observed in female monozygotic twins [19]. In our case-control study in North Norway [12], subgroup analysis suggests that the effect of UVR exposure on the MS risk might be driven by women, though the numbers are small [odds ratios for MS and summer outdoor activities at age 16-20 years, adjusted for cod liver oil supplement and dinner dishes of boiled or fried fish: women $\left(\mathrm{n}_{\text {cases }}=73\right) 0.51(95 \%$ CI 0.330 $0.778 ; \mathrm{p}=0.002)$; men $\left(\mathrm{n}_{\text {cases }}=38\right) 0.64(95 \%$ CI $0.363-$ $1.134 ; \mathrm{p}=0.127)]$.

\section{Does Vitamin D Sufficiency Protect against MS?}

The evidence from experimental and epidemiological data supporting the UVR/vitamin D hypothesis for MS is increasing. However, the critical time window during 
which the vitamin D status may have a persisting impact on the MS risk has not been finally established, and neither has the protective vitamin D level. Only a large randomized trial can answer the question of whether vitamin D supplementation can contribute to preventing MS and other disorders, e.g., diabetes type I, rheumatoid arthritis, inflammatory bowel disease, and certain cancers. It has to be kept in mind, though, that it is not clear whether all potential benefits of vitamin $\mathrm{D}$ can be provided by oral supplementation [49].

Judged by the common laboratory cutoff value of $40-$ $50 \mathrm{nmol} / \mathrm{l}$ of $25(\mathrm{OH}) \mathrm{D}$, vitamin D insufficiency is widespread in Europe and the US, but not in Norway [25, 28, 29]. If vitamin D sufficiency in Norway contributes to the lower MS risk than expected by latitude, this protection would be conferred by $25(\mathrm{OH}) \mathrm{D}$ levels in the lower sufficient range.

\section{Conclusions}

Norway is a discrete exception to the hypothesis that solar UVR exposure, mediated by vitamin $\mathrm{D}$, coheres with the latitude gradient seen for MS prevalence. When sun exposure is low, vitamin D sufficiency can be maintained through foods or supplements. The tradition of a highfish diet in a location with low solar UVR might explain why no latitude gradient of the MS risk is seen in Norway. It is biologically more plausible (and better studied) that vitamin $\mathrm{D}$ from fatty fish and cod liver oil plays a role rather than marine omega-3 PUFA, but even synergistic effects are possible. Vitamin D appears to play a role in the environmental effect in the complex aetiology of MS.

\section{Acknowledgment}

M.T.K. thanks Dr. G.C. Ebers, Oxford, UK, for helpful discussions.

\section{References}

1 Compston A, Coles A: Multiple sclerosis. Lancet 2002;359:1221-1231.

2 Hafler DA, Compston A, Sawcer S, et al: Risk alleles for multiple sclerosis identified by a genomewide study. N Engl J Med 2007;357: 851-862.

- 3 Harbo HF, Utsi E, Lorentzen AR, et al: Low frequency of the disease-associated $\mathrm{DRB1}^{*} 15-\mathrm{DQB1}{ }^{*} 06$ haplotype may contribute to the low prevalence of multiple sclerosis in Sami. Tissue Antigens 2007;69:299-304.

$\checkmark 4$ Gale CR, Martyn CN: Migrant studies in multiple sclerosis. Prog Neurobiol 1995;47: 425-448.

5 Ebers GC, Sadovnick AD, Dyment DA, et al: Parent-of-origin effect in multiple sclerosis: observations in half-siblings. Lancet 2004; 363:1773-1774.

-6 Dyment DA, Yee IM, Ebers GC, Sadovnick AD: Multiple sclerosis in stepsiblings: recurrence risk and ascertainment. J Neurol Neurosurg Psychiatry 2006;77:258-259.

7 Ebers GC, Sadovnick AD, Risch NJ: A genetic basis for familial aggregation in multiple sclerosis. Canadian Collaborative Study Group. Nature 1995;377:150-151.

-8 Ascherio A, Munger KL: Environmental risk factors for multiple sclerosis. I. The role of infection. Ann Neurol 2007;61:288-299.

-9 Ascherio A, Munger KL: Environmental risk factors for multiple sclerosis. II. Noninfectious factors. Ann Neurol 2007;61:504-513.

10 Pugliatti M, Rosati G, Carton H, et al: The epidemiology of multiple sclerosis in Europe. Eur J Neurol 2006;13:700-722. van der Mei IAF, Ponsonby AL, Blizzard L, Dwyer T: Regional variation in multiple sclerosis prevalence in Australia and its association with ambient ultraviolet radiation. Neuroepidemiology 2001;20:168-174.

12 Kampman MT, Wilsgaard T, Mellgren SI: Outdoor activities and diet in childhood and adolescence relate to MS risk above the Arctic Circle. J Neurol 2007;254:471-477.

13 Grant WB: Epidemiology of disease risks in relation to vitamin D insufficiency. Prog Biophys Mol Biol 2006;92:65-79.

14 Smolders J, Damoiseaux J, Menheere P, Hupperts R: Vitamin D as an immune modulator in multiple sclerosis, a review. J Neuroimmunol 2008;194:7-17.

15 Hayes CE, Cantorna MT, DeLuca HF: Vitamin D and multiple sclerosis. Proc Soc Exp Biol Med 1997;216:21-27.

16 Kira J: Multiple sclerosis in the Japanese population. Lancet Neurol 2003;2:117-127.

17 Vukusic S, Van Bockstael V, Gosselin S, Confavreux C: Regional variations of multiple sclerosis prevalence in French farmers. J Neurol Neurosurg Psychiatry 2007;78:707709.

18 van der Mei IAF, Ponsonby AL, Dwyer T, et al: Past exposure to sun, skin phenotype, and risk of multiple sclerosis: case-control study. BMJ 2003;327:316-321.

19 Islam T, Gauderman WJ, Cozen W, Mack TM: Childhood sun exposure influences risk of MS in monozygotic twins. Neurology 2007;69:381-388.
20 Freedman DM, Dosemeci M, Alavanja MCR: Mortality from multiple sclerosis and exposure to residential and occupational solar radiation: a case-control study based on death certificates. Occup Environ Med 2002;57: 418-421.

21 Goldacre MJ, Seagroatt V, Yeates D, Acheson ED: Skin cancer in people with multiple sclerosis: a record linkage study. J Epidemiol Community Health 2004;58:142-144.

22 Munger KL, Levin LI, Hollis BW, Howard NS, Ascherio A: Serum 25-hydroxyvitamin $D$ levels and risk of multiple sclerosis. JAMA 2006;296:2832-2838.

23 Willer CJ, Dyment DA, Sadovnick AD, et al: Timing of birth and risk of multiple sclerosis: population based study. BMJ 2005;330:120123.

24 Zittermann A: Vitamin D in preventive medicine: are we ignoring the evidence? $\mathrm{Br} \mathrm{J}$ Nutr 2003;89:552-572.

25 Holick MF: Vitamin D deficiency. N Engl J Med 2007;357:266-281.

26 Edvardsen K, Brustad M, Engelsen O, Aksnes L: The solar UV radiation level needed for cutaneous production of vitamin $\mathrm{D}_{3}$ in the face. A study conducted among subjects living at a high latitude (68 degrees N). Photochem Photobiol Sci 2007;6:57-62.

27 Brustad M, Alsaker E, Engelsen O, Aksnes L, Lund E: Vitamin D status of middle-aged women at 65-71 degrees $\mathrm{N}$ in relation to dietary intake and exposure to ultraviolet radiation. Public Health Nutr 2004;7:327-335. 
28 Nasjonalt råd for ernæring: Meyer H, Brunvand L, Brustad M, Holvik K, Johansson L, Paulsen JE: Tiltak for å sikre en god vitamin D-status i befolkningen. Rapport IS-1408. Oslo, Norwegian Nutrition Council, 2006.

-29 Brustad M, Edvardsen K, Wilsgaard T, et al: Seasonality of UV-radiation and vitamin D status at 69 degrees north. Photochem Photobiol Sci 2007;6:903-908.

-30 Brustad M, Braaten T, Lund E: Predictors for cod-liver oil supplement use - the Norwegian Women and Cancer Study. Eur J Clin Nutr 2004;58:128-136.

-31 Ross CM: Fish oil versus cod liver oil: is vitamin $\mathrm{D}$ a reason to go back to the future. J Am Board Fam Pract 2005; 18:445-446.

32 The Norwegian Food Composition Table 2006. Oslo, The Norwegian Food Safety Authority, Directorate for Health and Social Affairs and the University of Oslo. www. matportalen.no/matvaretabellen (accessed January 15, 2008).

>33 Welch AA, Lund E, Amiano P, et al: Variability of fish consumption within the 10 European countries participating in the European Investigation into Cancer and Nutrition (EPIC) study. Public Health Nutr 2002;5: 1273-1285.

34 Munger KL, Zhang SM, O’Reilly E, et al: Vitamin D intake and incidence of multiple sclerosis. Neurology 2004;62:60-65.

>35 Zhang SM, Willett WC, Hernan MA, Olek MJ, Ascherio A: Dietary fat in relation to risk of multiple sclerosis among two large cohorts of women. Am J Epidemiol 2000;152: 1056-1064.

-36 Engeset D, Alsaker E, Ciampi A, Lund E: Dietary patterns and lifestyle factors in the Norwegian EPIC cohort: the Norwegian Women and Cancer (NOWAC) study. Eur J Clin Nutr 2005;59:675-684.

-37 Brustad M, Sandanger T, Aksnes L, Lund E: Vitamin D status in a rural population of northern Norway with high fish liver consumption. Public Health Nutr 2004;7:783789.

38 Kris-Etherton PM, Taylor DS, Yu-Poth S, et al: Polyunsaturated fatty acids in the food chain in the United States. Am J Clin Nutr 2000;71(1 suppl):179S-188S.

-39 Johansson LR, Solvoll K, Bjorneboe GE, Drevon CA: Intake of very-long-chain $n-3$ fatty acids related to social status and lifestyle. Eur J Clin Nutr 1998;52:716-721.
40 Sugano M, Hirahara F: Polyunsaturated fatty acids in the food chain in Japan. Am J Clin Nutr 2000;71(1 suppl):189S-196S.

41 Swank RL, Lerstad O, Strom A, Backer J: Multiple sclerosis in rural Norway. Its geographic and occupational incidence in relation to nutrition. N Engl J Med 1952;246: $722-728$.

-42 Agranoff BW, Goldberg D: Diet and the geographical distribution of multiple sclerosis. Lancet 1974;2:1061-1066.

43 Lauer K: Diet and multiple sclerosis. Neurology 1997;49(2 suppl 2):S55-S61.

44 Ghadirian P, Jain M, Ducic S, Shatenstein B Morisset R: Nutritional factors in the aetiology of multiple sclerosis: a case-control study in Montreal, Canada. Int J Epidemiol 1998; 27:845-852.

45 Kurtzke JF: A reassessment of the distribution of multiple sclerosis. Part 1. Acta Neurol Scand 1975;51:110-136.

46 Kalueff AV, Minasyan A, Keisala T, et al: The vitamin D neuroendocrine system as a target for novel neurotropic drugs. CNS Neurol Disord Drug Targets 2006;5:363-371.

47 Calder PC: Polyunsaturated fatty acids and inflammation. Prostaglandins Leukot Essent Fatty Acids 2006;75:197-202.

48 Harbige LS, Sharief MK: Polyunsaturated fatty acids in the pathogenesis and treatment of multiple sclerosis. Br J Nutr 2007;98(suppl 1):S46-S53.

49 Lucas RM, Ponsonby AL: Considering the potential benefits as well as adverse effects of sun exposure: can all the potential benefits be provided by oral vitamin D supplementation? Prog Biophys Mol Biol 2006;92:140149.

50 Helland IB, Smith L, Saarem K, Saugstad OD, Drevon CA: Maternal supplementation with very-long-chain $n-3$ fatty acids during pregnancy and lactation augments children's IQ at 4 years of age. Pediatrics 2003;111:e39e44.

51 Dijck-Brouwer DA, Hadders-Algra M, Bouwstra $\mathrm{H}$, et al: Lower fetal status of docosahexaenoic acid, arachidonic acid and essential fatty acids is associated with less favorable neonatal neurological condition. Prostaglandins Leukot Essent Fatty Acids 2005;72: 21-28.

52 Stene LC, Ulriksen J, Magnus P, Joner G: Use of cod liver oil during pregnancy associated with lower risk of type I diabetes in the offspring. Diabetologia 2000;43:1093-1098.
53 Hypponen E, Laara E, Reunanen A, Jarvelin MR, Virtanen SM: Intake of vitamin D and risk of type 1 diabetes: a birth-cohort study. Lancet 2001;358:1500-1503.

54 Grytten N, Glad SB, Aarseth JH, et al: A 50year follow-up of the incidence of multiple sclerosis in Hordaland County, Norway. Neurology 2006;66:182-186.

55 Holmoy T: Vitamin D status modulates the immune response to Epstein Barr virus: synergistic effect of risk factors in multiple sclerosis. Med Hypotheses 2008;70:66-69.

56 Lucas R, Ponsonby AL, McMichael A, et al: Observational analytic studies in multiple sclerosis: controlling bias through study design and conduct. The Australian Multicentre Study of Environment and Immune Function. Mult Scler 2007;13:827-839.

57 Torkildsen O, Utsi E, Harbo HF, et al: Ethnic variations of IL-10 polymorphisms in a Sami and Norwegian population. Scand J Immunol 2005;62:71-74

58 Torkildsen O, Utsi E, Mellgren SI, et al: Ethnic variation of $F c$ gamma receptor polymorphism in Sami and Norwegian populations. Immunology 2005;115:416-421.

59 Gronlie SA, Myrvoll E, Hansen G, Gronning M, Mellgren SI: Multiple sclerosis in North Norway, and first appearance in an indigenous population. J Neurol 2000;247:129133.

60 Landtblom AM, Riise T, Kurtzke JF: Further considerations on the distribution of multiple sclerosis in Sweden. Acta Neurol Scand 2005;111:238-246.

-61 Pugliatti M, Riise T, Sotgiu MA, et al: Increasing incidence of multiple sclerosis in the province of Sassari, northern Sardinia. Neuroepidemiology 2005;25:129-134.

62 Giovannoni G, Cutter GR, Lunemann J, et al: Infectious causes of multiple sclerosis. Lancet Neurol 2006;5:887-894.

63 McGrath J: Does 'imprinting' with low prenatal vitamin $\mathrm{D}$ contribute to the risk of various adult disorders? Med Hypotheses 2001; 56:367-371.

64 Spach KM, Hayes CE: Vitamin $\mathrm{D}_{3}$ confers protection from autoimmune encephalomyelitis only in female mice. J Immunol 2005; 175:4119-4126.

65 Orton SM, Herrera BM, Yee IM, et al: Sex ratio of multiple sclerosis in Canada: a longitudinal study. Lancet Neurol 2006;5:932936. 